\title{
Progress on Preparation of pH/Temperature-Sensitive Intelligent Hydrogels and Applications in Target Transport and Controlled Release of Drugs
}

\author{
Lixian Li $\mathbb{D},{ }^{1,2}$ Yongpeng He, ${ }^{1}$ Xiaodong Zheng $\mathbb{D},{ }^{1}$ Lin $Y i,{ }^{1}$ and Weiqi Nian $\mathbb{D}^{1}$ \\ ${ }^{1}$ Chongqing University Cancer Hospital \& Chongqing Cancer Institute \& Chongqing Cancer Hospital, Chongqing 400030, China \\ ${ }^{2}$ Department of Chemistry, The University of British Columbia, Vancouver, British Columbia, Canada V6T 1Z1
}

Correspondence should be addressed to Lixian Li; lilixian2010@yahoo.com, Xiaodong Zheng; zxd052005@sohu.com, and Weiqi Nian; nwqone@126.com

Received 24 April 2019; Accepted 12 March 2020; Published 6 January 2021

Guest Editor: Parisa P. Abadi

Copyright $\odot 2021$ Lixian Li et al. This is an open access article distributed under the Creative Commons Attribution License, which permits unrestricted use, distribution, and reproduction in any medium, provided the original work is properly cited.

Hydrogels with three-dimensional network structure, hydrophilic, and insoluble in water which are ideal carrier materials for intelligent drug delivery systems. Intelligent hydrogel has become a research frontier and hotspot because of its intelligence, high efficiency, safety, and convenience in drug controlled and prolonged release. It has a broad application prospect in the medicine and biomedicine fields and can lead the medicine fields into a new era of "precise treatment." Based on the latest research progress, the main preparation methods of hydrogel and the development of the drug delivery system are briefly introduced. The most promising three intelligent hydrogels in the human physiological environment, namely, $\mathrm{pH}$ responsiveness, temperature responsiveness, and $\mathrm{pH} /$ temperature dual responsiveness, are emphatically reviewed. Their release mechanisms, targeting transport, and controlled-prolonged release of drug are also discussed. In addition, some suggestions for the main problems and future development were given.

\section{Introduction}

Hydrogel is a three-dimensional crosslinked network structure which is formed by hydrophilic polymers through chemical bond, ammonia bond, Van der Waals' force, or physical interaction. In 1960, Wichterle and Lim prepared a polymer network structure by using the crosslinking 2-hydroxyethyl methacrylate (pHEMA) [1]. It is a milestone discovery in the history of hydrogel development. In 1970s, polyethylene glycol (PEG) hydrogel attracted attentions, and it was widely used in controlled delivery vector of drugs due to its good biocompatibility and strong resistance to protein adsorption. Research concerns shift from the relatively simple watersoluble macromolecular network gel into hydrogel systems produced by changes of environmental factors, such as temperature, $\mathrm{pH}$, and biomolecular concentration. Size and shape of hydrogel can be controlled by regulating these environmental factors. Hence, hydrogel is often used as an intelligent material [2]. Among them, temperature sensitive hydrogel is the environmental sensitive system which has been studied the earliest and used most extensively [3]. The intelligent temperature-sensitive hydrogel is the consequence of equilibrium among different hydrophilic, hydrophobic effects, and Van der Waals' force in the gel system. $\mathrm{pH}$ sensitive hydrogel is the second common environmental sensitive system. Since $\mathrm{pH}$-sensitive hydrogel generally carries weak acid or alkaline groups, the ionization of groups is sensitive to external $\mathrm{pH}$. Internal and external ion concentrations redistribute and reach a new equilibrium upon changes of external $\mathrm{pH}$. Research and development (R\&D) of a new drug is time-consuming and requires high cost. The annual expenses for drug R\&D in the American pharmaceutical industry exceeded 20 billion of dollars in 1990s, which was further increased to 72 billion of dollars in 2004 . Such annual expense was still increasing. The cost for new drug $R \& D$ soared up significantly. The average R\&D cost of the American pharmaceutical company for each new drug increased from 231 million of dollars in 1987 to 802 million 
of dollars in 2000 and even soared up to 1.4 billion of dollars in 2004. The average time consumption for R\&D of a new drug is about 14 years. It has been reported by studies that $39 \%$ of $R \& D$ failures of new drugs are caused by poor dynamic characteristics of drugs in the human body, another $29 \%$ of failures are caused by the unsatisfying curative effect, and $21 \%$ of failures are attributed to toxicity and side effects of drugs [4].

The drug delivery system (DDS) which achieves rapid development in recent years can transport drugs to the target position according to the desired dosage and action time through the perfect combination of drugs and carrier. In addition, DDS controls drug delivery through the feedback regulation mechanism of the human body, thus realizing the goal of curing diseases. Moreover, this DDS can relieve general toxic and side effects of drugs and improve therapeutic effect of diseases. Controlled releasing of drugs is an extensively studied and perfect technology in DDS. It is a new technology that can control delivery speed and directional release of drugs. On the one hand, hydrogel not only has weak adhesion to cells and proteins but also has excellent biocompatibility with blood, fluid, and tissues of the human body. On the other hand, hydrogel with abundant water has soft texture similar with biological tissues and weak reactivity with antigen of the human body. Hydrogel which is prepared by nontoxic materials can cause small harms to the human body [5]. Under the dual effects of release by hydrogel deformation and self-diffusion, drugs can be released to the target position slowly according to the desired dosage. Hydrogel has advantages of quantitative, directional, and stable delivery of drugs. Therefore, intelligent hydrogel gradually becomes the first chose of carrier of DDS [6, 7]. The second generation DDS of an intelligent drug delivery system which could response to external environmental factors (e.g. $\mathrm{pH}$, temperature, and light) was developed by some polymer materials around 1980 . The second generation DDS realized intelligent delivery of drugs and became one of research hotspots in the field of medicines. The third generation DDS of a targeted intelligent drug delivery system was launched in 2010. Different from the second generation DDS, the third generation DDS involves a covalent modification of targeted group by drug carriers. This targeted group has the higher selectivity of tumors and thereby can deliver drugs to the target position of focus actively. This is significantly different from the passive transport depending on enhanced permeation and retention (EPR) of solid tumors. The third generation DDS can not only shorten in vivo circulation of drugs and prevent drug leakage or inactivation but also decrease dosage and side effect of drugs as well as mitigate pains of patients [8]. Intelligent hydrogel which is the drug carrier is the key component of DDS and the primary factor that influences the effect of drugs. At present, applications of intelligent hydrogels in targeted delivery and controlled releasing of drugs have become a research front and hotspot in the field of medicine. Research on applications of intelligent hydrogels in controlled drug releasing has extremely important academic values and promising application prospects in clinics.

\section{Hydrogel Preparation Methods}

Hydrogel can be hydrolyzed quickly due to the natural supermolecule matrix. Hence, hydrogel often fails to meet the requirements in biomedicine applications $[9,10]$. It is of important significance to explore and search new preparation and modification methods or materials. Physical crosslinking and chemical ligation are two common preparation methods of hydrogel. Physical crosslinking is simple and convenient. However, hydrogel prepared by physical crosslinking has some disadvantages, such as insufficient strength and tenacity, instability, and easy hydrolysis. Chemical ligation is relatively complicated and has high requirements on technologies and chemical reactions. Nevertheless, it can improve mechanical properties and structural stability of hydrogel significantly.

2.1. Physical Crosslinking Method. Physical crosslinking among polymers is generally realized by interaction of noncovalent bonds (hydrophobic, ionic and intermolecular hydrogen bonds, subject-object, or various covalent bonds) [9-11]. Due to the strong hydrophobic interaction in aqueous solution, hydrogel can be prepared simply and directly by amphiphilic block polymers. This becomes the most common method of hydrogel preparation based on physical crosslinking.

(1) Stereocomplexation: stereocomplexation, or known as the cocrystallization of two enantiomers, can be used to prepare injectable hydrogel. Enantiomer is mainly used to prepare in situ hydrogel. Hydrogel can be formed by coupling of poly-L-lactide (PLLA) and poly-D-lactide (PDLA) with hydrophilic polymers (e.g., glucan) in aqueous solution. Firstly, protein drugs are dissolved in the solution of gel precursor, through which the protein drug is encapsulated in the hydrogel network [10]. Without any surfactant or chemical ligation agents, Jiang et al. first proposed the unique network structure on the basis of hydrophobic associations of the HMPAM and SDS in the aqueous solution [11]. This micelle cluster is the crosslinking center of the hydrogel network and gives a solid three-dimensional structure of hydrogel. Compared with hydrogel prepared by chemical ligation, HA gel shows unusual swelling-deswelling behaviors in water. Additionally, the existence of micelle cluster increases mechanical properties of HA gel and shows ultra-strong self-healing ability in applications of biomedicine technologies in the future

(2) Polypeptide chain interaction: polypeptide physical hydrogel is mainly prepared by self-assembly of molecules. Due to biodegradation and biocompatibility, polypeptide only produces amino acids during degradation, which may not cause adverse impacts on the living body. Polypeptide will not cause immunoreactions and tissue inflammation after entering into the living body. Besides, polypeptide has multiple configurations, such as spiral, overlapping, and irregular 
curling structures. Self-assembly of some polypeptides occurs in the physiological environment. The produced hydrogel can be transported in different environments easily. This type of hydrogels possesses a promising prospect in studies on controlled drug delivery technology and new support for cell therapy as well as tissue engineering

Yang et al. connected peptide chains with the selfassembly ability onto the skeleton composed of the linear hydrophilic compound poly [N-(2-hydroxypropyl) methacrylamide] (HPMA) through covalence bonds, forming the self-assembly peptide chain grafted compounds (Figure 1) [12]. They found that HPMA in the copolymer would not hinder self-assembly of the peptide chain, but the length of the peptide chain, and the peptide chain grafted onto each skeleton affected the formation of self-assembly gel significantly. Kopecek et al. [13] prepared a hybrid hydrogel which was assembled by water-soluble polymers and proteins with a double helix structure. This hybrid hydrogel could be transformed from synergic conformation to a double helix structure upon induction of temperature.

2.2. Chemical Ligation Method. Chemical ligation is one of the most important methods to prepare hydrogel. Firstly, initiator is added for grafting monomers onto groups of raw materials. Secondly, crosslinking agent is added for crosslinking of different polymers, forming a stable three-dimensional network structure. This three-dimensional network structure only swells, but is not dissolved. The mechanical properties of the three-dimensional network structure are stronger than those of a physical crosslinking network. Photopolymerization chemical ligation, native chemical ligation, and click chemistry are highly appreciated by the public due to the simple operation and high transformation rate [10].

2.2.1. Photopolymerization Chemical Ligation. Under the existence of photoactive compounds (or known as photocatalysts), ultraviolet or visible light irradiation can trigger in situ polymerization, thus producing three-dimensional networked hydrogels with intramolecular or intermolecular crosslinking structures. This process is the photopolymerization. The photopolymerization chemical ligation is characteristic of mild conditions, controllable process, few byproducts, and no use of toxic initiator. The mechanism of photopolymerization chemical ligation is introduced as follows: photoinitiator forms free radicals under irradiation of ultraviolet or visible lights, and polymerization of monomers is triggered by these free radicals. This method has some prominent advantages, such as short photocuring (several seconds to several minutes), successful reaction under room temperature or human body temperature, no use of any organic solvents, and temporal-space regulation. For this reason, photopolymerization chemical ligation has been widely applied in biomedicine after it was reported by Hubbell et al. [14]. Liu et al. [15] prepared the pH-sensitive hydrophobic polymethylacrylic acid hydrogel through polymerization of benzoin ethyl ether (photoinitiator), crylic acid-2ethylhexyl acrylate (hydrophobic monomer), tripropylene glycol diacrylate (crosslinking agent), and methyacrylic acid under ultraviolet lights. Moreover, they used hydroxyanisole as a model drug and discussed the drug delivery law of polymethacrylic hydrophobic gel.

2.2.2. Native Chemical Ligation. Dawson et al. proposed the native chemical ligation for the first time in 1994. Thioesters and peptide amino acid with an $\mathrm{N}$-end react firstly to produce thioester crosslinked compounds. Subsequently, these thioester crosslinked compounds were rearranged, forming a natural peptide bonds (Figure 2) [16]. The native chemical ligation is widely used in big polypeptide proteins with medium molecular weight and dendritic polymers based on polypeptides.

2.2.3. Click Chemistry. Click chemistry is one type of reaction that synthesizes various structural molecules quickly and effectively through the splicing module. Click chemistry has many advantages: firstly, good spatial orientation and stereoselectivity. Secondly, strong thermomechanical effect: click chemistry often involves reactants with instable thermodynamics or stable products. Thirdly, high reaction rate: water generally causes no negative impacts on click chemistry. In addition, single product: click chemistry generally has no additive reaction of producing by-products or condensation reaction that produces water as the by-product.

In 2006, Hilborn synthesized poval with azide groups, and alkynyl functionalized through "click chemistry" for the first time [17]. Later, he added $\mathrm{CuSO}_{4}$ and vitamin A sodium salt into the system to synthesize the vinol hydrogel. In 2008, he also discovered the formation of oxime, semicarbazone, and tetrahydrothiazole crosslinking points through the reaction between polymer multifunctional crosslinking agents and hyaluronic acids [18]. The multifunctional crosslinking agent based on PVA has good cell compatibility and shows no toxicity after $48 \mathrm{~h}$. It can be shaped quickly under $\mathrm{pH}=7.4$ and $37^{\circ} \mathrm{C}$. The Karl Barry Sharpless research team who won the Nobel Prize in Chemistry in 2014 reported a click chemical reaction based on sexavalence sulfur fluoride exchange (SuFEx) in Angewandte Chemie. In the follow-up five years, "click chemistry" between azides and alkyne becomes one of hotspot methods to prepare hydrogel network structures.

\section{Drug Delivery System}

The drug delivery system (DDS) refers to a new form of drug administration that can release drugs at the fixed time, to the target position, and in the determined dosage by regulating the internal structure of drug carriers. It is characteristic of high efficiency, low toxicity, targeted delivery, few times of drug delivery, and high safety. Specifically, the controlled drug releasing system and targeted controlled drug releasing system based on reversible intelligent hydrogel carrier have attracted wide research attentions in recent years $[19,20]$.

3.1. Controlled Drug Releasing System. The controlled drug releasing system refers to a drug loading system that can delay the releasing rate of drugs from preparations and release drugs to the acting organ or target tissues and cells 


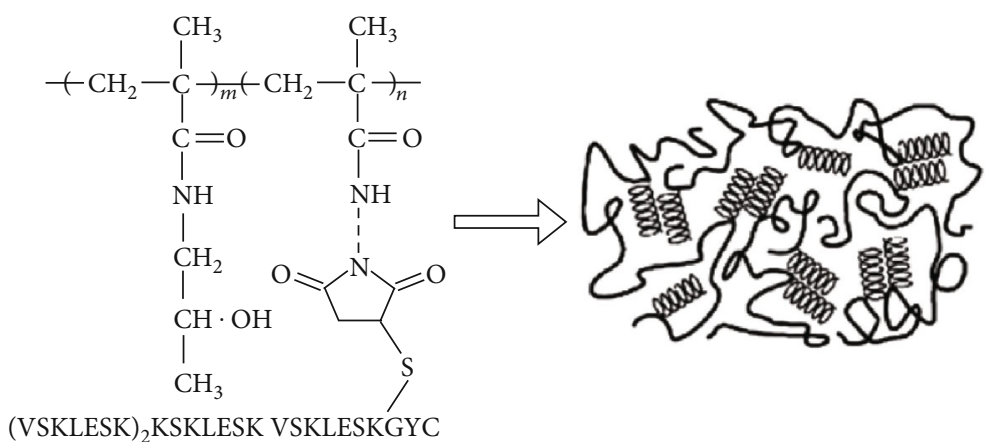

FIGURE 1: Diagram of hydrogel self-assembled from graft copolymer and structure of graft copolymer of HPMA (reproduced from reference [12] with copyright permission from john wiley and sons).

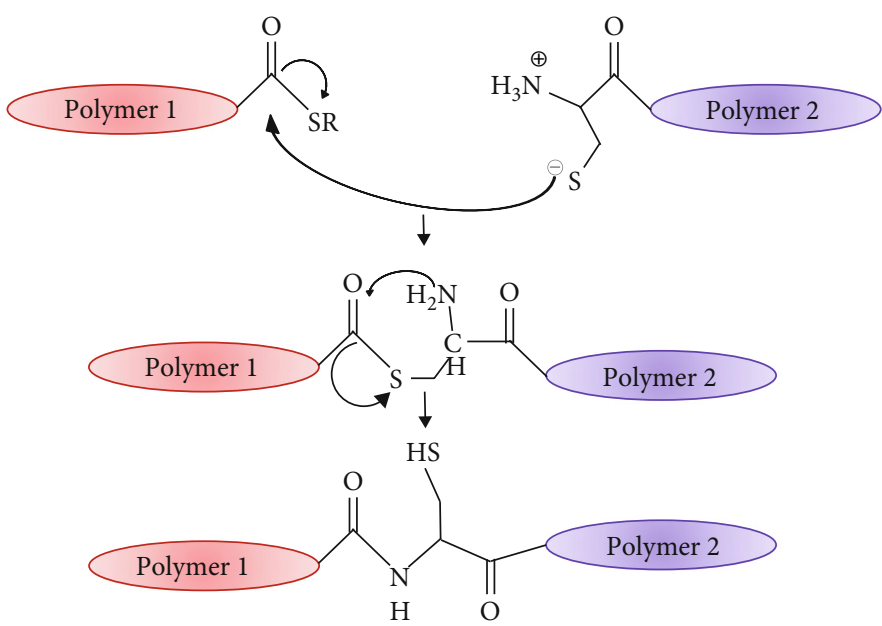

FIGURE 2: Coupling mechanism of native chemical ligation of two polymers (reproduced from reference [16] with copyright permission from ACS Publications).

at a constant speed. It can decrease the drug absorption rate of the human body, delay the action of drugs, eliminate peaks and valleys of drugs, and decrease times of drug administrations, thus realizing better therapeutic effect. The microballoon oral-taking system, osmotic pump tablets oral-taking system, and microballoon injecting system are controlled drug releasing systems.

3.2. Targeted Controlled Drug Releasing System. For some clinical diseases like liver cancer, lung cancer, and solid tumor, large dosage general administration of drugs cannot develop effect of drugs better and cause extremely significant toxic and side effects to normal organ tissues and human body. For example, the ordinary administration mode of drugs generally cannot achieve the satisfying effect of drugs for brain or spinal cord diseases, which is caused by physiological barriers. However, the targeted controlled drug releasing system can concentrate drugs at the target organ tissues or in target cells through local drug delivery based on carriers, ligands or antibodies, or general blood circulation, thus lowering drug concentration in normal positions as much as possible. For instance, directed drug releasing to target tissues and organs through carriers like lipidosome, microcapsule, and microballoon can not only decrease the administration dosage of drugs but also improve the therapeutic effect and lower toxic and side effects of anticancer drugs [21]. In addition, some antibodies or ligands could be modified onto the carrier surface in accordance to specific diseases, so that the drug carrier can develop immunity or affinity specificity. As a result, the drug carrier is easier to be recognized by tumor tissues or cancer cells and can deliver drugs to the target tissues or cells more efficiently [22]. Due to the strong interaction with cancer cells, folic acid can be used to modify the carrier of anticancer drugs to enhance targeting ability of drugs. Mackiewicz et al. [23] prepared the polyethylene glycol-b-polyglycolic acid (PEG-b-PLA) polymer and then modified it with folic acid and fluorescence needle through click chemistry. On this basis, a nano drug-carrying micelle is self-assembled, which realizes the dual function of targeted drug delivery and cell imaging. Except for folic acid, some carbohydrates also can be used in targeted DDS. Ladmiral et al. [24] modified galactose onto vesicae through the reversible addition-fragmentation transfer (RAFT) polymerization technique for targeted transport of rhodamine B.

Specificity is the most outstanding advantage of the targeted drug releasing system. It overcomes the low target sensitivity of biochemistry. With the continuous innovation of new DDS and continuous updating of new carrier materials, 
the connotation and denotation of the drug carrier are updating continuously. For instance, the development of gel, micelle, nanoparticles, and vesicae overcome many disadvantages of anticancer drugs, such as strong toxic and side effects, easy decomposition, and sudden releasing. They can improve efficiency of targeted drug delivery and weaken side effects, thus enabling to achieve better therapeutic effect [8].

\section{Application of Intelligent Hydrogels in Controlled Drug Releasing Systems}

Compared with ordinary DDS, using intelligent hydrogels with many special performances in the controlled drug releasing system has many evident advantages, such as delaying the drug delivery, prolonging action time of drugs, increasing bioavailability of drugs, stable drug concentration and decrease fluctuation of drug concentration, target transport and controlled releasing of drugs, reducing dosage of drugs, mitigating or preventing toxic and side effects, preventing influences by the "first-pass effect" of gastrointestinal environment and liver as well as the gastrointestinal assimilation resistance, and optimizing therapy and improve compliance of patients.

The drug-carrying and controlled releasing behaviors of xylan P (NIPAM-G-AA) hydrogel network was studied in detail [25]. The NIPAM-G-AA hydrogel network presents a porous structure. The special pores of hydrogel allow drugs wrapped onto hydrogel matrix. The controlled drug releasing rate is determined by the diffusion coefficient of micromolecules or macromolecules in the gel network [25]. It is reported by studies that temperature/pH-sensitive NIPAMG-AA hydrogel can control drug releasing in gastric fluid and intestinal fluid well.

4.1. Drug Releasing Mechanism of pH-Sensitive Intelligent Hydrogel and Its Applications in Controlled Drug Releasing Systems. There are three major types of $\mathrm{pH}$-sensitive materials, namely, cationic hydrogel, anionic hydrogel, and zwitter-ion hydrogel [26]. The $\mathrm{pH}$-sensitive cationic hydrogels (generally polyacrylamides) mainly include ionizable functional groups of $-\mathrm{NHR},-\mathrm{NR}_{2}$, and $-\mathrm{NH}_{2}$. Amino exists as ions in the acid environment. Repulsion among ions increases the distance between hydrogel chains, and more water molecules enter into the hydrogel chain, thus enhancing the swelling ratio. Hydrogen-bond interactions in hydrogel in the alkaline environment further compact the network structure better and thereby decrease the swelling ratio [26]. The $\mathrm{pH}$-sensitive anionic hydrogel (generally acids like polyacrylic acid) mainly exists in $-\mathrm{COO}^{-}$. $-\mathrm{COO}^{-}$is protonized into $-\mathrm{COOH}$ in the acid environment. Due to interaction of groups, the hydrogel network structure is more compacted, which makes it difficult to develop swelling by water absorption. In the alkaline environment, $-\mathrm{COOH}$ is changed to $-\mathrm{COO}^{-}$, and the electrostatic repulsion between carboxylic acids further extends the network structure, which is conducive to strengthen water absorption and increase the swelling ratio [26, 27]. Zwitter-ion hydrogel mainly carries acid-based groups. $-\mathrm{COOH}$ is ionized, while amino is protonized in the alkaline environment. On the contrary, $-\mathrm{COOH}$ is proto- nized, and amino is ionized in the acid environment. The swelling ratio decreases as approaching to the neutral state. In a word, zwitter-ion hydrogel has ionization of groups in either acid or alkaline environment. Ion strength is the major influencing factor of the swelling ratio of zwitter-ion hydrogel [26]. The phase changes of the swelling performance of all three hydrogels with $\mathrm{pH}$ are shown in Figure 3 [27].

The most ideal controlled drug releasing is to control releasing of drugs in accordance with psychological needs at specific positions (target). $\mathrm{pH}$-triggered control is the most attractive target releasing way $[28,29] . \mathrm{pH}$ in gastrointestinal tract of the human body ranges between 1 and 7.5 (1-3 in stomach, 5-6 in saliva, 6.4-7.0 in colon, and 6.6-7.5 in intestines). $\mathrm{pH}$-sensitive intelligent hydrogel can perceive changes of the physiological environment in the human body, thus adjusting the dynamics of drug releasing. The swelling behavior of hydrogel also changes with $\mathrm{pH}$, forming a switching key. Hydrogel has promising application prospects in the field of medicine [16].

The $\mathrm{pH}$-sensitive hydrogel can regulate releasing of drugs in different physiological positions effectively by taking advantages of great differences of $\mathrm{pH}$ between the stomach environment $(\mathrm{pH} \approx 1.2)$ and intestinal environment $(\mathrm{pH} \approx 7.4)$ [30]. Cationic hydrogel achieves the minimum swelling ratio under neutral conditions, and only few drugs are released from hydrogel. For example, caffeine which is loaded onto the copolymer hydrogel of polymethyl methacrylate and dimethylamino-ethyl polymethacrylate releases drugs when $\mathrm{pH}$ ranges between 3 and 5 . Based on this characteristic behavior, it can prevent releasing drugs with poor tastes in the neutral oral environment and thereby improve taste of drugs. The controlled drug releasing in stomach can be realized by the semiinterpenetrating network type of cationic hydrogel. For example, the semi-interpenetrating network hydrogels formed by chitosan and polyethylene glycol have good swelling characteristics in the acid environment (close to $\mathrm{pH}$ in stomach). These hydrogels can be used as intelligent hydrogel carriers for targeted releasing of antibiotic drugs in the stomach environment. Some hydrogels which achieves the minimum swelling ratio in the acid environment and maximum swelling ratio in the neutral environment can be used as a potential carrier of intestinal or colon specificity drugs [31].

$\mathrm{Xu}$ [32] and Feng et al. [33] synthesized the methacrylic acid-poloxamer copolymer hydrogel and the multilayer sodium alginate tech grade hydrogel for oral DSS, respectively. Releasing and swelling of these hydrogels are inhibited in the acid environment, but they can release drugs quickly in neutral or alkaline environments. Wu et al. [34] prepared pH-sensitive in situ gel for delivery of ophthalmic baicalin by using carbopol P974 as the matrix and macromolecular crosslinked polymer hydroxypropyl methylcellulose hypromellose (HPM C-E4M) as the thickener. This in situ gel achieved the best stability when $\mathrm{pH}$ is about 6.0 , but the drug releasing rate was increased significantly at $\mathrm{pH}=5.8$. This in situ gel improved the intraocular comfort of gel and compliance of patients. Due to the unique $\mathrm{pH}$-dependent swellingdeswelling controlled drug releasing characteristics, $\mathrm{pH}$ sensitive hydrogel has been extensively used in the oral 


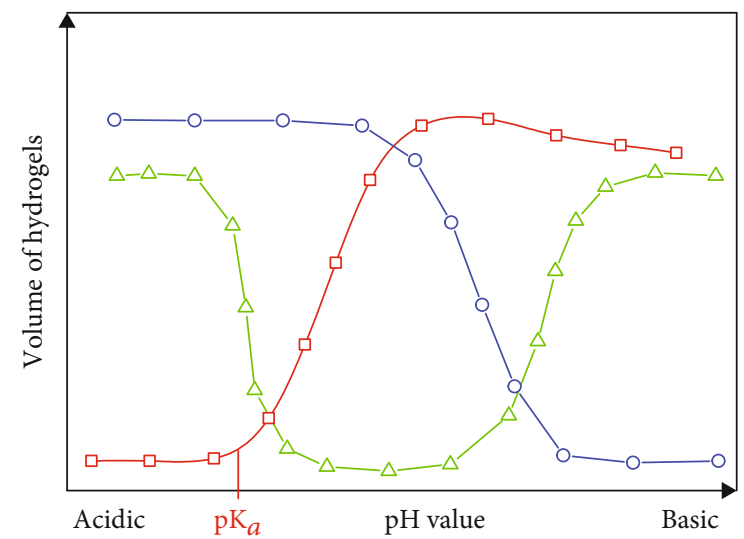

FIgure 3: Phase transition behavior of different types of $\mathrm{pH}$ sensitive hydrogels. Adapted from [27], acidic hydrogels (red rectangle) are ionised by deprotonation in basic solutions, which have an excess of hydroxyl groups. Basic hydrogels (blue circle) swell in acidic solutions due to the ionisation of their basic groups by protonation. Amphiphilic hydrogels (green triangle) contain both acidic and basic groups. Therefore, they show two phase transitions. (reproduced from reference [27] without permissions that are required for this figure as the original publication is open access).

administration of drugs, traumas, and ophthalmic diseases. However, most associated studies are dealing with experiments. Further, studies on toxic characteristics of carrier materials, encapsulation rate, and selection of polymers are still needed. Moreover, mutual interference of sensitive units in the drug carrier with dual or multiple responses might weaken and even cause disappearance of one response sensitivity.

\subsection{Drug Releasing Mechanism of Temperature-Sensitive} Intelligent Hydrogel and Its Applications in Controlled Drug Releasing Systems. Temperature-sensitive intelligent hydrogel refers to the gel that swells or contracts of volume upon changes of ambient temperature. This type of hydrogel has hydrophobic monomer and hydrophilic monomer. The interaction between hydrophobic and hydrophilic monomers and hydrogen bonds between molecular chains in hydrogel are influenced by temperature, thus destroying the internal structure of hydrogel and causing volume swelling or contraction [35]. Temperature-sensitive intelligent hydrogel can be divided into low critical solution temperature (LCST) type and upper critical solution temperature (UCST) type. There are three major drug releasing modes and mechanisms of temperature-sensitive intelligent hydrogel [36]:

4.2.1. Squeezing Mode. Squeezing mode releases drugs through the quick contraction of the network structure of hydrogels. Hydrogel adsorbs drugs by swelling behavior under low temperature, but squeezes drugs out of the gel through contraction when the ambient temperature exceeds LCST [37]. This controlled drug releasing path is shown in Figure 4. It has some disadvantages: drugs encapsulated in hydrogel can be released outward slowly through diffusion under the swelling state. However, hydrogel releases drugs too quickly at contraction after LCST, which fails to realize the goal of long-term drug releasing.

4.2.2. “On-off” Controlling Mode. The “on-off” controlling mode of the hydrogel system can be further divided into the shell "on-off" controlling mode and micropore grafted "on-off" controlling mode. In the shell "on-off” controlling mode, the hydrogel contracts when the ambient temperature exceeds LCST, which induces contraction of the hydration shell on the surface and produces a thin compacted layer keeping water and drugs within hydrogel. This is known as the "off" state. When the ambient temperature is lower than LCST, the compact layer on the hydrogel surface swells, and it is in the "on" state to diffuse drugs from hydrogel freely [38]. This process is shown in Figure 5. The micropore grafted "on-off" controlling mode is formed by grafting hydrogel molecular chains into the matrix of porous material. When the ambient temperature is lower than LCST, the grafted chain of hydrogel can be extended freely to cover micropores in matrix. This is known as the "off" state. When the ambient temperature is higher than LCST, the macromolecular chain grafted onto the hydrogel contracts and micropores on the microballoon surface are showed, turning to the "on" state [39]. Under this circumstance, drugs diffuse outward, and the goal of controlled drug releasing is realized. This process is shown in Figure 6.

4.2.3. Free Diffusion. When the ambient temperature is lower than LCST, hydrophilic drugs in the swelling hydrogel can be released to the external environment through permeation due to the concentration difference between saturated drugs in hydrogel and the external environment. This presents the Fickian releasing mechanism. The diffusion rate is related with swelling degree of hydrogel as well as the drug structure and size [40]. The releasing process is shown in Figure 7.

Temperature-sensitive intelligent hydrogel contains thermosensitive block, which can produce reversible sol-gel phase transition under changes of ambient temperature. Therefore, temperature-sensitive macromolecular materials are extensively used, including cellulose, polyacrylamides, and polysaccharide derivatives.

Although low-temperature swelling and hightemperature contraction $N$-isopropyl acrylamide (PNIPAM) polymer produce phase transition under LCST $\left(28-32^{\circ} \mathrm{C}\right)$ and can make quick responses to temperature changes, its applications in drug delivery are restricted for biotoxicity and nondegradability. For degradation of hydrogel polymer, Jeong et al. [41] synthesized the degradable temperaturesensitive PEO-PLLA-PEG polymer hydrogel. However, UCST of this degradable temperature-sensitive PEO-PLLAPEG polymer hydrogel was only $45^{\circ} \mathrm{C}$, and the polymer solution was easy to form gel to block needle under room temperature. Therefore, this UCST hydrogel is not suitable to be the carrier for drug delivery.

The LCST value of hydrogel can be adjusted by copolymerization of hydrophilic or hydrophobic monomers. Chung et al. [42] prepared gel through copolymerization of hydrophobic butyl methacrylate (BMA) and isopropyl acrylamide, and LCST of this gel could be adjusted. The gel swelled to 


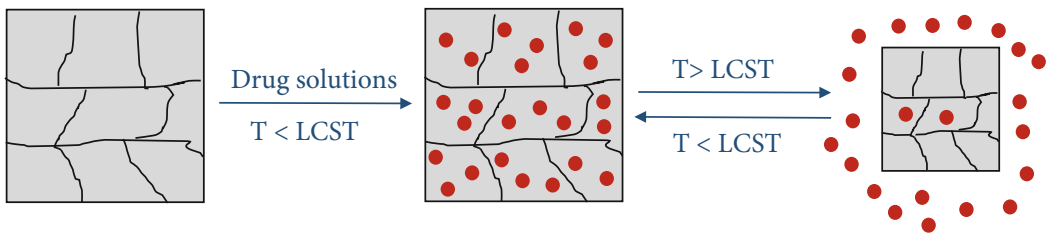

FIgURE 4: Extrusion mode of drug delivery from temperature-sensitive hydrogels.

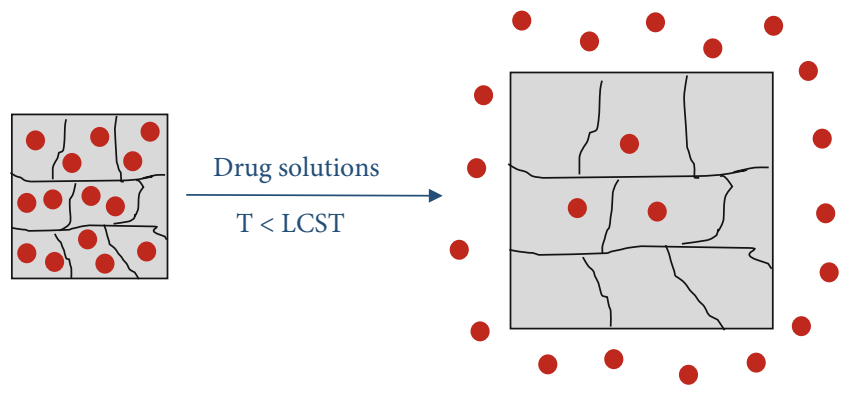

FIgURE 5: Skin layer "on-off” modes of drug delivery.

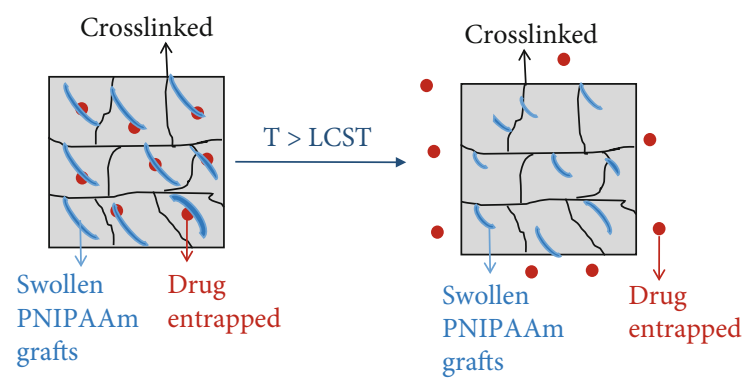

Figure 6: Grafted system “on-off modes of drug delivery.

release drugs at $10^{\circ} \mathrm{C}$, but it contracted and stopped drug releasing at $30^{\circ} \mathrm{C}$. The surface contraction layer formed by gel copolymerization plays an important role in controlled drug releasing. Liu et al. [43] prepared a pulse drug releasing system based on temperature-sensitive gel with switching functions. When the ambient temperature was higher than LCST, the interaction of lipotropic chains and intermolecular hydrogen bonds form a polymer network to contract the gel and release drugs. When the ambient function was lower than LCST, the gel swelled again and stopped releasing of drugs. Hsiue et al. [44] developed a temperature-sensitive preparation based on PNIPAM to cure glaucoma. Ophthalmic preparation was a solution under room temperature, but it forms gel immediately after applied in eyes, thus releasing drugs continuously and stably. The action time of drugs can be prolonged by 5-7 times than direct administration of drugs.

Targeted thermal chemotherapy guided by temperaturesensitive hydrogel is another hotspot of thermal chemotherapy of tumors. It controls drug releasing by changing local temperature. When the temperature is higher than LCST, drugs carried on the hydrogel carrier are released quickly to the local heating position of tumor, thus producing the thermal targeting effect. It improves the therapeutic effect through dual advantages of temperature sensitivity and thermal chemotherapy. Chilkoti et al. [45] heated the artificial temperature-sensitive elastin polypeptide which was loaded with ELP-ADR to increase local drug concentration by $2-3$ times of that under room temperature.

The temperature response rate can be adjusted by changing the gel network structure [46]. For example, PNIPAM with amine end is prepared by using aminoethyl mercaptan as the chain transfer agent. Next, the macromolecular monomer PNIPAM with polymerizable groups at end could be prepared through condensation reaction of active ester monomers and the end amino. Under the action of crosslinking agents, NIPAM monomer and this macromolecular monomer PNIPAM copolymerize, finally forming the grafted PNIPAM hydrogel. The swelling ratio and swelling rate of the grafted PNIPAM hydrogel are higher than those of ordinary PNIPAM networked hydrogel [47]. This is mainly because the graft chain has higher degree of freedom (DOF) and can move freely and absorb water more. The controlled drug releasing behavior is closely related with the network structure of hydrogel. Therefore, the drug releasing rate and amount can be controlled by adjusting temperature and gel structure [48]. However, monomer and crosslinking agent used in PNIPAM-based hydrogel have no biocompatibility and biodegradability. For example, hydrogel carrying acrylamide will stimulate blood platelet in blood at contact. Therefore, it still needs abundant studies on biotoxicity to realize clinical applications of PNIPAM-based hydrogels. Alternatively, nontoxic hydrogels with biocompatibility and biodegradability which are similar with polyethylene glycol and polylysine shall be developed [49]. The hydrophobic drug delivery process by the temperature-sensitive hydrogel dendritic polymer which is modified by the target ligands and fluorescence needle was researched [50]. When drugs are delivered to the human body, heats in the blood may trigger amphiphilic polymers and target points to produce multifunctional dendrimers, achieving the synergetic enhancement successfully [50].

At present, many studies have applied multiple temperature-sensitive intelligent hydrogels to carry or bond antitumor drugs to treat tumors [28], such as natural polymers (e.g. chitosans, celluloses, and hyaloplasm), polyolefins, polyethers, PEG/polyesters, antitumor drugs (e.g. taxol, adriamycin amycin, and cis-platinum), protein drugs (e.g. insulin, interferon, and VEGF), antibiotic drugs, and DNA [51]. PEG-PLGA which is a temperature-sensitive hydrogel that carries taxol has been applied in clinical treatment of tumors. The administration dosage of PEG-PLGA $\left(0.48 \mathrm{mg} / \mathrm{m}^{2} /\right.$ day $)$ is significantly lower than the traditional administration dosage $\left(17 \mathrm{mg} / \mathrm{m}^{2} /\right.$ day $)$, but it improves the 


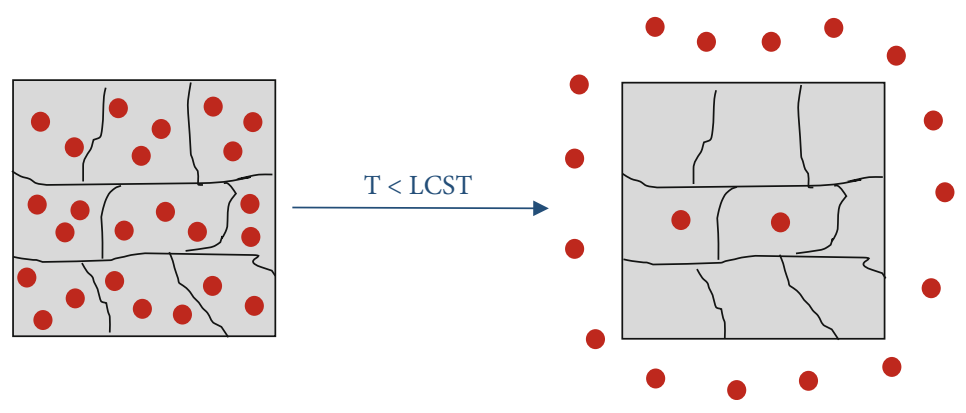

Figure 7: Free modes of drug delivery.

therapeutic effect and weakens the general toxic and side effects. The effect of PEG-PLGA can last for 6 weeks, which prevent repeated injection of drugs and mitigate pains of patients. PEG-PLGA is mainly applicable to solid tumor which cannot be excised [52]. Peng et al. [53] performed an injection therapy to liver cancer HCC by using the temperature-sensitive intelligent hydrogel PCL-PEG-PCL with radionuclide (188Re-Tincolloid) and chemotherapeutics (lipidosome adriamycin amycin), which prolonged the action time of $188 \mathrm{Re}$-Tincolloid in HCC. The tumor elimination rate of the combined group reached as high as $80 \%$. Therefore, the combination of the temperature-sensitive intelligent hydrogel carrier and drugs has a promising application prospect. The critical solution temperatures of different temperature-sensitive intelligent hydrogels are shown in Table 1.

4.3. Drug Releasing Mechanism of $p H /$ Temperature-Sensitive Intelligent Hydrogel and Its Applications in Controlled Drug Releasing Systems. Intelligent hydrogel can adapt to external environmental changes (e.g., $\mathrm{pH}$ value, temperature, light, electricity, magnetic field, and chemical substance) through volume changes or phase transition. Intelligent hydrogels are used more and more in high-tech fields, such as drug transport, biosensor, and brake [58]. Currently, intelligent response hydrogels generally can be divided into singleresponse intelligent hydrogels (e.g., $\mathrm{pH}$ value, temperature, and magnetic field), dual-response intelligent hydrogels (e.g., temperature-pH response, temperature-magnetic field response, and $\mathrm{pH}$-magnetic field response), and multiresponse intelligent hydrogels (e.g., temperature-pH-magnetic field multi-response and temperature- $\mathrm{pH}$-light multiresponse) [57]. Since temperature and $\mathrm{pH}$ are not only the most important parameters to maintain normal life activities and the important conditions for survival of bacteria and virus, but also the most common and easiest to be controlled stimuli in the human body and biomedicine [59]. As a result, $\mathrm{pH} /$ temperature-sensitive hydrogel is the most popular intelligent hydrogel in the field of targeted controlled drug releasing.

$\mathrm{pH} /$ temperature-sensitive hydrogel is mainly synthesized by using monomers sensitive to $\mathrm{pH}$ and temperature through graft polymerization, crosslinking, or interpenetrating networks. Substantially, $\mathrm{pH} /$ temperature-sensitive hydrogel is the further development of single-sensitivity hydrogel. It can change the response range by adjusting the mixing ratio of $\mathrm{pH}$ and temperature to meet demands of different fields. $\mathrm{pH} /$ temperature-sensitive hydrogel can adapt to the complicated physiological environment like human fluid better, because it can perceive dual stimulus responses to $\mathrm{pH}$ and temperature. In addition, interaction among multiple materials can not only enhance mechanical strength and biological adhesion of hydrogels but also improve accuracy of controlled drug releasing. It is a kind of promising carrier for controlled drug releasing.

Drug releasing based on $\mathrm{pH} /$ temperature-sensitive hydrogel can be divided into follow four steps: Firstly, drugs are dissolved out and enter into surrounding polymers or pores. Secondly, concentration gradient makes drugs passing through the polymer barrier through molecular diffusion. Thirdly, drugs are desorbed from the polymer surface. Finally, drugs are diffused to fluid of the human body or environmental media. The drug releasing is mainly realized by the squeezing effect and dissolution effect [60]. The drug releasing mechanism based on $\mathrm{pH} /$ temperature-sensitive hydrogel is shown in Figure 8.

Hydrogel and drugs mainly combine through physical and chemical modes [61]. Physical combination refers to the electric charge effect between ionic polymers and charged drugs. Cationic polymers (e.g., functional groups of amino) can be used to control release of anionic drugs (e.g., benzocaine). Anionic polymers (e.g., hyaluronic acid) can entrap cationic drugs (local anesthetics) and control the drug releasing by taking advantage of the electric charge effect. For uncharged monomer or polymer, anionic polymer can be used to synthesize hydrogel to delayer or strengthen drug releasing by taking the advantages of adsorption to specific drugs. The chemical combination controls the drug releasing through the covalent bonds (hydrolysis or partial hydrolysis) between hydrogels and drugs [61].

Surrounding environmental conditions of tumor are different from normal physiological conditions of the human body. Tumor temperature is about $42^{\circ} \mathrm{C}$, which is higher than normal temperature $\left(37^{\circ} \mathrm{C}\right)$ of the human body. $\mathrm{pH}$ ranges between 7.0 and 7.4 in the surrounding environment of tumor and ranges between 6.9 and 7.0 in tumor cells, which is lower than the normal psychological value of the human body $(\mathrm{pH}=7.4)$. $\mathrm{pH} /$ temperature-sensitive hydrogel can control the drug releasing speed and increase bioavailability in addition to targeted drug delivery [62]. It has promising application prospects in the field biomedicine. Therefore, R\&D of $\mathrm{pH} /$ temperature-sensitive hydrogel 
TABLE 1: Critical solution temperature of temperature-sensitive intelligent hydrogel.

\begin{tabular}{|c|c|c|}
\hline Name & $\begin{array}{l}\text { Critical solution } \\
\text { temperature } /{ }^{\circ} \mathrm{C}\end{array}$ & References \\
\hline Poly N-piperidine & 5.5 & {$[54]$} \\
\hline BMA-PNIPAM & 10 & {$[42]$} \\
\hline Poly N-methyl-N-PNIPAM & 22.3 & {$[54]$} \\
\hline Acrylamide-L-proline methylase & 24 & {$[54]$} \\
\hline Poly N-PNIPAM & 30.9 & {$[54]$} \\
\hline Poly-N,N-diethyl acrylamide & 32 & {$[37]$} \\
\hline Chitosan/ $\beta$-sodium glycerophosphate/gelatin hydrogels & 32.6 & {$[55]$} \\
\hline Chitosan/gelatin/genipin/ $\beta$-sodium glycerophosphate hydrogel & 37 & {$[3]$} \\
\hline Polyvinyl methyl ether & 38.0 & {$[54]$} \\
\hline PEO-PLLA-PEG polymer hydrogel & 45 & [41] \\
\hline Poly N-ethyl methacrylamide & 50.0 & {$[54]$} \\
\hline Poly N-ethyl acrylamide & 72.0 & {$[54]$} \\
\hline N-TBA/M,N-dimethylacrylamide copolymer & $20-80$ & {$[56]$} \\
\hline $\begin{array}{l}\text { Methacrylic acid 2-(2-methoxy ethoxy) ethyl ester (MEO2MA)-methacrylic acid oligosity } \\
\text { (glycol)ester (OEGMA) copolymer hydrogel }\end{array}$ & $26-90$ & {$[57]$} \\
\hline
\end{tabular}
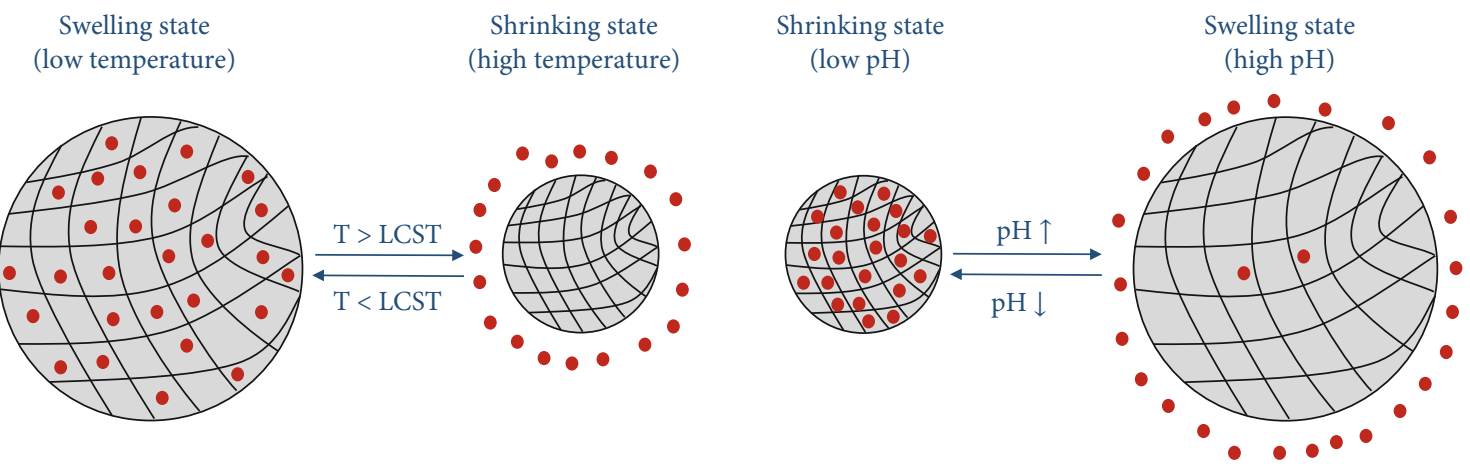

Figure 8: Drug release mechanism of hydrogels at different temperatures and $\mathrm{pH}$.

is of important significance to targeted accurate treatment of tumors.

Huynh et al. [62] prepared a four-arm polyethylene glycol-polyurethane $\mathrm{pH} /$ temperature-sensitive intelligent hydrogel which was loaded with chlorambucil, which showed excellent hydrophilicity and biocompatibility. It could develop reversible swelling contraction with changes of $\mathrm{pH}$ and ambient temperature. This hydrogel can be adsorbed surrounding tissues as a response to $\mathrm{pH}$ and temperature of the human body ( $\mathrm{pH} 7.4,37^{\circ} \mathrm{C}$ ), so that drugs can be released at a constant speed through free diffusion in $14 \mathrm{~d}$ and finally dissolved gradually. Huynh et al. [63] prepared $\mathrm{pH} /$ temperature-sensitive hydrogel through polymerization of poly $\beta$ carbamic acid ester embedded with adriamycin amycin and polyethylene glycol. Under the in vivo psychological conditions (temperature $=37^{\circ} \mathrm{C}$ and $\mathrm{pH}=7.4$ ), gel can be formed quickly to prolong the drug releasing time to five weeks.

Lo et al. [64] prepared the pluronic-polyacrylic acid $\mathrm{pH} /$ temperature-sensitive hydrogel loaded with pharmorubicin. This is a type of the ideal degradable drug releasing system. After oral taking of aqueous solution of drugs under room temperature, this $\mathrm{pH} /$ temperature-sensitive hydrogel was changed to gel when body temperature and $\mathrm{pH}$ reached $37^{\circ} \mathrm{C}$ and 6.8 , thus enabling to deliver drugs to colon continuously in $12 \mathrm{~h}$. Seo et al. [65] prepared a $\mathrm{pH} /$ temperature-sensitive intelligent hydrogel which was loaded with recombinant human granulocyte colony-stimulating factormacrophage colony stimulating factor (M-CSF) and chitosan of cyclophosphamide. This hydrogel was changed to gel under body temperature and psychological $\mathrm{pH}\left(37^{\circ} \mathrm{C}\right.$ and $\mathrm{pH} 7.4$ ) to release drugs continuously to tumor tissues in 7 d. Moreover, this hydrogel can be degraded and eliminated gradually and improve the targeted treatment and lethality of tumor cells.

$\mathrm{pH} /$ temperature-sensitive hydrogel can be prepared from copolymerization of N-NIPA and monomers containing groups $\left(-\mathrm{COOH}\right.$ or $-\mathrm{NH}_{2}$ ) which are easy to be hydrolyzed or ionized. Polymerization of ionized $\mathrm{pH}$-sensitive groups in temperature-sensitive hydrogel can affect the swelling behavior of hydrogel. Katime et al. [66] synthesized a $\mathrm{pH} /$ temperature-sensitive hydrogel N-PNIPAM-co-2-methylene-succinic acid)P (NIPA-co-MBDA) based on free radical polymerization, finding that $\operatorname{LCST}\left(22-37^{\circ} \mathrm{C}\right)$ of gels prepared by different mixing ratios of monomers was 
TABLE 2: Applications of different hydrogels in controlled drug releasing.

\begin{tabular}{|c|c|c|c|c|}
\hline $\begin{array}{l}\text { Type of } \\
\text { response }\end{array}$ & Hydrogel polymers & Drugs & Duration & References \\
\hline \multirow{4}{*}{ pH-sensitive } & $\begin{array}{l}\text { Hemicellulose grafted } \\
\text { polyacrylic acid }\end{array}$ & Aspirin & $12 \mathrm{~h}$ & [73] \\
\hline & $\begin{array}{l}\text { Chitosan (CS)-polyvinyl } \\
\text { alcohol (PVA) }\end{array}$ & Dexamethasone/aspirin & $7 \mathrm{~h}$ & {$[74]$} \\
\hline & Polyacrylic acid & Prednisolone & $5 \mathrm{~h}$ & {$[75]$} \\
\hline & $\begin{array}{c}\text { Chitosan (CS)-polyvinyl } \\
\text { pyrrolidone (PVP) }\end{array}$ & Oral antibiotic & Releasing rate $=73.2 \%$ in $3 \mathrm{~h}(\mathrm{pH}=1.0)$ & {$[76]$} \\
\hline \multirow{4}{*}{$\begin{array}{l}\text { Temperature- } \\
\text { sensitive }\end{array}$} & $\begin{array}{l}\text { Polypropyl caprolactone } \\
\text { glutamic acid }\end{array}$ & TAX & $21 d$ & {$[77]$} \\
\hline & $\begin{array}{l}\text { Chitosan/sodium } \\
\text { glycerophosphate }\end{array}$ & PYM & $18 \mathrm{~d}$ & {$[78]$} \\
\hline & $\begin{array}{l}\text { Polyglycolic acid and } \\
\text { polylactic acid }\end{array}$ & Cytarabine & $10 \mathrm{~d}$ & {$[79]$} \\
\hline & $\begin{array}{l}\text { Poly (N-PNIPAM)- } \\
\text { carboxymethyl chitosan }\end{array}$ & cis-Platinum & $16 \mathrm{~d}$ & {$[80]$} \\
\hline \multirow{4}{*}{$\begin{array}{l}\mathrm{pH} \\
\text { temperature- } \\
\text { sensitve }\end{array}$} & $\begin{array}{l}\text { Four-arm polyethylene } \\
\text { glycol-polyurethane }\end{array}$ & Chlorambucil & $14 \mathrm{~d}$ & {$[62]$} \\
\hline & Pluronic-polyacrylic acid & Pharmorubicin & $12 \mathrm{~h}$ & {$[64]$} \\
\hline & $\begin{array}{l}\text { Poly } \beta \text {-carbamic acid } \\
\text { ester/polyethylene glycol }\end{array}$ & Adriamycin amycin & $35 \mathrm{~d}$ & {$[63]$} \\
\hline & (N-PNIPAM-cocrylic acid) & Riboflavin (vitamin B2) & $\begin{array}{l}\text { Releasing rate }=91.5 \% \text { in } 7 \mathrm{~h}\left(\mathrm{pH}=7.0, \mathrm{~T}=52^{\circ} \mathrm{C}\right) \\
\text { Releasing rate }=75 \% \text { in } 3.5 \mathrm{~h}\left(\mathrm{pH}=2.0, \mathrm{~T}=52^{\circ} \mathrm{C}\right)\end{array}$ & {$[81]$} \\
\hline
\end{tabular}

different. In other words, increasing the content of 2methylene-succinic acid can increase LCST of the hydrogel, and LCST varies under different $\mathrm{pH}$ values. Hoare et al. [67] synthesized the $\mathrm{pH} /$ temperature-sensitive functional microgel of NIPAM-inyl stearate (VAc), which could realize ionization in an extremely narrow $\mathrm{pH}$ range. In the same time, the volume of the synthesized microgel was swelled by 4 times of that of ordinary hydrogel when psychological temperature reached ionization temperature. However, they also discovered in the temperature-sensitivity process that deswelling behaviors took place at complete protonization of the microgel. In this case, phase transition would not be observed even though the temperature was increased to $70^{\circ} \mathrm{C}$. Huang et al. [68] found that P (NIPAM-co-AA) hydrogel loaded with aspirin could release drugs more quickly in the pH7.4 environment under $37^{\circ} \mathrm{C}$ compared with that under $25^{\circ} \mathrm{C}$. Given the same temperature $\left(37^{\circ} \mathrm{C}\right)$, the drug releasing rate at $\mathrm{pH} 7.4(>40 \%$ in $12 \mathrm{~h}$ ) was significantly higher than that at $\mathrm{pH} 1.0(<20 \%$ in $12 \mathrm{~h})$. This reveals that the prepared P(NIPAM-co-AA) hydrogel could realize directional release of most aspirin in intestines.

In addition, $\mathrm{pH} /$ temperature-sensitive hydrogel also can be used in controlled release of insulin. Ramkissoon et al. [69] synthesized N-NIPAM- (temperature-sensitive-) BMA-AAc ( $\mathrm{pH}$ sensitive) trimer hydrogel with different molecular weights by using insulin as the protein model drugs. It found that the release of insulin was closely related with the molecular weight of trimer under $37^{\circ} \mathrm{C}$ and $\mathrm{pH} 7.4$. Under low molecular weight, the release of insulin was controlled by solubility of the trimer. Under high molecular weight, the hydrogel with low molecular weight can be used in fast drug releasing in duodenum, while hydrogel with moderate molecular weight can be used in targeted drug releasing in the small intestine and hydrogel with high molecular weight can be used in targeted drug releasing in colon.

Lee et al. [70] prepared injectable $\mathrm{pH} /$ temperature-sensitive hydrogel based on oligomerization ( $\beta$-polyurethane) (OAEU) polymer, which can be transformed into gel through phase transition under psychological conditions $\left(37^{\circ} \mathrm{C}\right.$, $\mathrm{pH}$ 7.4). This hydrogel could be retained in a living body for at least 2 weeks, and the phase-transition temperature can be regulated by changing the OAEU concentration. Ding [71] synthesized polyethylene oxide (PEO)-polyphenyl ether-polyethylene oxide with end capped by polymer glycol chitosan/benzaldehyde. With high sensitivity to $\mathrm{pH}$ and temperature, this $\mathrm{PEO}$-polyphenyl ether-polyethylene oxide is coated with DOX.HCL and prednisolone and formed hydrogels under the body temperature of $37^{\circ} \mathrm{C}$. It released drugs continuously when $\mathrm{pH}$ decreased to weak acidity (6.5-6.8). Guo et al. [72] prepared a $\mathrm{pH} /$ temperature-sensitive intelligent hydrogel based on carboxymethyl chitosan, which showed good reversibility. Under $37^{\circ} \mathrm{C}$, the drug releasing rate of coenzyme $\mathrm{A}$ in acid buffer solution was $22.6 \%$, and it reached as high as $89.1 \%$ in the intestinal environment of the human body. This indicated that this hydrogel is an excellent carrier for controlled releasing of the drug CoA. Applications of different hydrogels in controlled drug releasing are shown in Table 2.

The multiresponse intelligent DDS (e.g., $\mathrm{pH} /$ temperature, $\mathrm{pH} /$ glucose, and $\mathrm{pH}$ /oxidization/reducing) is significantly superior to single-response DDS. For example, the 
temperature-sensitive hydrogel solution is easy to be transformed into gel and block the needle when it is injected to the human body. This problem can be solved effectively by embedding a $\mathrm{pH}$-sensitive segment. The introduction of $\mathrm{pH}$-sensitive functional groups solves and improves the needle blockage and poor water solubility of hydrogel polymers successfully, so that hydrogel can be used in package transport of ionic protein drugs. It provides more selection for the optimal design of hydrogel structures. However, $\mathrm{pH} /$ temperature-sensitive hydrogel still faces with some problems $[47,62,82,83]$ : firstly, the package rate of drugs is low, and the preparation technique of hydrogel is complicated. Secondly, some polymers contain cytotoxic groups (e.g., polyacrylic acids), thus resulting in many side effects, such as inflammation and destroying cells or proteins. In addition, it lacks a deep study on the formation mechanism of multiresponse hydrogel and the relationship between degradation rate of hydrogel polymer and controlled drug releasing performance. This influences the optimal design and applications of gel materials.

\section{Conclusions and Prospects}

With the rapid development of life sciences, pharmaceutics, genomics, intelligent polymer materials, molecular biological technologies, and relevant interdisciplines, intelligent targeted drug delivery is an optimal administration mode of drugs. In 2015, Obama, the present of the United States, proposed a "Precision Medicine Plan", in which he pointed out that the core of precision medicine lies in precision rather than medicine. It fully demonstrates that giving appropriate treatment to appropriate patients at appropriate time can realize precision truly. Precision medicine will surely bring a fresh new era of medicine. An intelligent DDS was established to make targeted transport and controlled release of drugs based on its specific responses to the environment. The targeted quantitative releasing of drugs at appropriate time is an invincible opponent of many refractory diseases.

$\mathrm{R} \& \mathrm{D}$ of pharmaceutic preparations conforms to the principle of "high efficiency, quick efficiency and long-term efficiency," "small toxicity, side effect and dosage," and "conveniences for production, transport, storage, carrying and taking." As the carrier material of pharmaceutic preparation, the intelligent response hydrogel is characteristic of intelligent, efficient, safe, and convenient controlled drug releasing. It has attracted wide research attentions. However, it still has some problems $[67,70,74,82-85]$ : firstly, the response time of temperature-sensitive hydrogel is still long to the drug carrying system. In clinical applications, temperature-sensitive hydrogels have poor hydrophilicity, low relative molecular weight, and initial sudden releasing problems of proteins. Secondly, the controlled releasing of anticancer drugs by chemical gel which can make quick response can only form hydrogel by in vivo chemical reaction. It is difficult to assure effective entrapment of drugs. In addition, this might trigger side reaction of polymers and drugs, thus inactivating drugs. Thirdly, degradation products of some polymers (e.g., PLA and PLGA) can lower the $\mathrm{pH}$ value in the injection position, resulting in inflammation, cell damages, or protein problems.
In addition, it is necessary to increase entrapment rate of hydrogel to drugs, improve biocompatibility, biodegradability, and mechanical properties of hydrogel and lower its toxicity. Besides, the in vivo degradation process of hydrogel as well as metabolic products and elimination time shall be interpreted. Cytotoxicity, biotoxicity, and therapeutic effect after drug loading of the hydrogel system have to be verified significantly.

As a new intelligent DDS, $\mathrm{pH}$ /temperature-sensitive hydrogel has achieved outstanding progresses. Its applications in targeted drug delivery and controlled drug release have been a research hotspot in the field of medicine. With the continuous development of intelligent polymer materials, genomics, molecular biological technologies, and relevant interdisciplines, the intelligent response hydrogels will achieve more extensive applications in targeted drug delivery and controlled drug releasing and take the leadership in the new era of "Precision Treatment".

\section{Conflicts of Interest}

The authors declare that there is no conflict of interest regarding the publication of this paper.

\section{Acknowledgments}

The authors gratefully acknowledge financial support from the Fundamental Research Funds for the Central Universities (2019CDYGYB022), Performance Motivation and Guidance Special Project of Chongqing Science \& Technology Commission (cstc2017jxj1130006), Science and Technology Research Program of Chongqing Municipal Education Commission (No. KJQN201800111), and Chongqing Cancer Hospital 1110 Talent Project.

\section{References}

[1] O. Wichterle and D. Lím, "Hydrophilic gels for biological use," Nature, vol. 185, no. 4706, pp. 117-118, 1960.

[2] J. Kopecek, "Hydrogels: from soft contact lenses and implants to self-assembled nanomaterials," Journal of Polymer Science Part A: Polymer Chemistry, vol. 47, no. 22, pp. 5929-5946, 2009.

[3] C. Likai, Research on preparation and performances of temperature-sensitive chitosan hydrogel drug carrier, Suzhou University, 2015.

[4] B. Wang, T. Siahaan, and R. A. Soltero, Drug Delivery: Principle and Applications, pp. 29-51, John Wiley and Sons. Incorporated, New Jersey, 2005.

[5] Z. Yifeng, "Environmental-sensitive intelligent micromolecular organic gel materials," Progress in Chemistry, vol. 23, no. 1, pp. 125-135, 2011.

[6] J. F. Almeida, P. Ferreira, A. Lopes, and M. H. Gil, "Photocrosslinkable biodegradable responsive hydrogels as drug delivery systems," International Journal of Biological Macromolecules, vol. 49, no. 5, pp. 948-954, 2011.

[7] L. Chao, P (N-MAM-co-DMAA), and P (N-MAM-co-AA), Research on preparation of intelligent hydrogels and its controlled drug releasing performance, Xinyang Normal University, 2015. 
[8] W. Luo, Preparation of pH/temperautre-sensitive polymer (PCL-PDMAEMA-PPEGMA)_4 and its controlled drug releasing hydrogels, South China University of Technology, 2018.

[9] S. J. de Jong, S. C. de Smedt, M. W. C. Wahls, J. Demeester, J. J. Kettenes-van den Bosch, and W. E. Hennink, "Novel self-assembled hydrogels by stereocomplex formation in aqueous solution of enantiomeric lactic acid oligomers grafted to dextran," Macromolecules, vol. 33, no. 10, pp. 3680-3686, 2000.

[10] S. R. Van Tomme, G. Storm, and W. E. Hennink, "In situ gelling hydrogels for pharmaceutical and biomedical applications," International Journal of Pharmaceutics, vol. 355, no. 1-2, pp. 1-18, 2008.

[11] G. Jiang, C. Liu, X. Liu et al., "Network structure and compositional effects on tensile mechanical properties of hydrophobic association hydrogels with high mechanical strength," Polymer, vol. 51, no. 6, pp. 1507-1515, 2010.

[12] J. Yang, C. Xu, P. Kopečková, and J. Kopeček, "Hybrid hydrogels self-assembled from HPMA copolymers containing peptide grafts," Macromolecular Bioscience, vol. 6, no. 3, pp. 201-209, 2006.

[13] C. Wang, R. J. Stewart, and J. Ř. KopeČek, "Hybrid hydrogels assembled from synthetic polymers and coiled-coil protein domains," Nature, vol. 397, no. 6718, pp. 417-420, 1999.

[14] A. S. Sawhney, C. P. Pathak, and J. A. Hubbell, "Bioerodible hydrogels based on photopolymerized poly(ethylene glycol)co-poly(.alpha.-hydroxy acid) diacrylate macromers," Macromolecules, vol. 26, no. 4, pp. 581-587, 1993.

[15] Y. Y. Liu, W. Q. Liu, W. X. Chen, L. Sun, and G. B. Zhang, "Investigation of swelling and controlled-release behaviors of hydrophobically modified poly(methacrylic acid) hydrogels," Polymer, vol. 48, no. 9, pp. 2665-2671, 2007.

[16] T. Vermonden, R. Censi, and W. E. Hennink, "Hydrogels for protein delivery," Chemical Reviews, vol. 112, no. 5, pp. 2853-2888, 2012.

[17] D. A. Ossipov and J. Hilborn, "Poly(vinyl alcohol)-based hydrogels formed by "click chemistry"," Macromolecules, vol. 39, no. 5, pp. 1709-1718, 2006.

[18] D. A. Ossipov, S. Piskounova, and J... Hilborn, "Poly(vinyl alcohol) cross-linkers for in vivo injectable hydrogels," Macromolecules, vol. 41, no. 11, pp. 3971-3982, 2008.

[19] Z. Dagen, Z. Liu, Q. Zuo, Y. Huang, and W. Xie, “Applications and research progresses of intelligent hydrogels in controlled drug releasing system," Material Review, vol. 26, no. 11, pp. 83-88, 2012.

[20] L. He, Q. Zuo, S. Xie, Y. Huang, and W. Xue, "Intelligent hydrogels for drug delivery system," Recent Patents on Drug Delivery \& Formulation, vol. 5, no. 3, pp. 265-274, 2011.

[21] L. Ma, Preparation and characterization of $\mathrm{pH} /$ temperaturesensitive hydrogel particles/ microspheres and their applications in controlled drug releasing, Lanzhou University, 2010.

[22] E. R. Gillies and J. M. J. Fréchet, "Dendrimers and dendritic polymers in drug delivery," Drug Discovery Today, vol. 10, no. 1, pp. 35-43, 2005.

[23] N. Mackiewicz, J. Nicolas, N. Handké et al., "Precise engineering of multifunctional PEGylated polyester nanoparticles for cancer cell targeting and imaging," Chemistry of Materials, vol. 26, no. 5, pp. 1834-1847, 2014.

[24] V. Ladmiral, M. Semsarilar, I. Canton, and S. P. Armes, "Polymerization-induced self-assembly of galactose-functionalized biocompatible diblock copolymers for intracellular delivery,"
Journal of the American Chemical Society, vol. 135, no. 36, pp. 13574-13581, 2013.

[25] C. Gao, J. Ren, C. Zhao et al., "Xylan-based temperature/pH sensitive hydrogels for drug controlled release," Carbohydrate Polymers, vol. 151, pp. 189-197, 2016.

[26] M. Ying, Research on Oral Colon-Targeted Hydrogels as the Controlled Drug Releasing System, Ji'nan University, 2018.

[27] A. Richter, G. Paschew, S. Klatt, J. Lienig, K. F. Arndt, and H. J. Adler, "Review on hydrogel-based $\mathrm{pH}$ sensors and microsensors," Sensors, vol. 8, no. 1, pp. 561-581, 2008.

[28] O. Werzer, S. Tumphart, R. Keimel, P. Christian, and A. M. Coclite, "Drug release from thin films encapsulated by a temperature -responsive hydrogel," Soft Matter, vol. 15, no. 8, pp. 1853-1859, 2019.

[29] W. Zhang, X. Jin, H. Li, R. R. Zhang, and C. W. Wu, "Injectable and body temperature sensitive hydrogels based on chitosan and hyaluronic acid for $\mathrm{pH}$ sensitive drug release," Carbohydrate Polymers, vol. 186, pp. 82-90, 2018.

[30] Z. Wang, X. Han, Y. Wang et al., "Facile preparation of low swelling, high strength, self-healing and $\mathrm{pH}$-responsive hydrogels based on the triple-network structure," Frontiers of Materials Science, vol. 13, no. 1, pp. 54-63, 2019.

[31] Y. Chen and P. Sun, "pH-sensitive Polyampholyte microgels of poly(acrylic acid-co-Vinylamine) as injectable hydrogel for controlled drug release," Polymers, vol. 11, no. 2, p. 285, 2019.

[32] H. Xu, P. Tian, H. Zhao, and J. Zheng, "Diffusion behaviors of drugs in $\mathrm{pH}$-sensitive polymethylacrylic acid-poloxamer hydrogels," Applied Chemistry, vol. 18, no. 4, pp. 305-308, 2001.

[33] C. Feng, R. Song, G. Sun et al., "Immobilization of coacervate microcapsules in multilayer sodium alginate beads for efficient oral anticancer drug delivery," Biomacromolecules, vol. 15, no. 3, pp. 985-996, 2014.

[34] H. Wu, Z. Liu, L. Li, N. Li, and Q. Guo, "In vitro study on baicalin $\mathrm{pH}$-triggered ophthalmic in situ gel system," Chinese Journal of New Drugs, vol. 6, pp. 508-513, 2011.

[35] G. Zhang and X. Jiang, "Temperature responsive nanoparticles based on PEGylated Polyaspartamide derivatives for drug delivery," Polymers, vol. 11, no. 2, p. 316, 2019.

[36] J. Yang, Construction of PLGA Microsphere/P(NIPAAm-CoAAm) Hydrogel Compound System and Research on Controlled Drug Releasing Performances, Chongqing University, 2011.

[37] H. G. Schild, "Poly (N-isopropylacrylamide) : experiment, theory and application," Progress in Polymer Science, vol. 17, no. 2, pp. 163-249, 1992.

[38] T. Okano, Y. H. Bae, H. Jacobs, and S. W. Kim, “Thermally onoff switching polymers for drug permeation and release," Journal of Controlled Release, vol. 11, no. 1-3, pp. 255-265, 1990.

[39] I. Ankareddi and C. S. Brazel, "Synthesis and characterization of grafted thermosensitive hydrogels for heating activated controlled release," International Journal of Pharmaceutics, vol. 336, no. 2, pp. 241-247, 2007.

[40] L. Jiang, Y. Feng, L. Sheng, and D. Xu, “Advances in research on drug release mechanisms and modes of themosensitive gel," China Journal of Chinese Materia Medica, vol. 33, no. 1, pp. 105-107, 2008.

[41] B. Jeong, Y. H. Bae, D. S. Lee, and S. W. Kim, "Biodegradable block copolymers as injectable drug-delivery systems," Nature, vol. 388, no. 6645, pp. 860-862, 1997.

[42] J. E. Chung, M. Yokoyama, M. Yamato, T. Aoyagi, Y. Sakurai, and T. Okano, "Thermo-responsive drug delivery from 
polymeric micelles constructed using block copolymers of poly( $\mathrm{N}$-isopropylacrylamide) and poly(butylmethacrylate)," Journal of Controlled Release, vol. 62, no. 1-2, pp. 115-127, 1999.

[43] X. M. Liu, B. Yang, Y. L. Wang, and J. Y. Wang, "New nanoscale pulsatile drug delivery system," Chemistry of Materials, vol. 17, no. 11, pp. 2792-2795, 2005.

[44] G. H. Hsiue, S. H. Hsu, C. C. Yang, S. H. Lee, and I. K. Yang, "Preparation of controlled release ophthalmic drops, for glaucoma therapy using thermosensitive poly- $\mathrm{N}$-isopropylacrylamide," Biomaterials, vol. 23, no. 2, pp. 457-462, 2002.

[45] A. Chilkoti, M. R. Dreher, D. E. Meyer, and D. Raucher, "Targeted drug delivery by thermally responsive polymers," Advanced Drug Delivery Reviews, vol. 54, no. 5, pp. 613-630, 2002.

[46] S. Pacelli, P. Paolicelli, M. Avitabile et al., "Design of a tunable nanocomposite double network hydrogel based on gellan gum for drug delivery applications," European Polymer Journal, vol. 104, pp. 184-193, 2018.

[47] T. Pan, Preparation of pH/Temperature-Sensitive Hdyrogels and its Performances in Controlled Drug Releasing, University of Science and Technology of China, 2011.

[48] A. Allı and B. Hazer, "Poly(N-isopropylacrylamide) thermoresponsive cross-linked conjugates containing polymeric soybean oil and/or polypropylene glycol," European Polymer Journal, vol. 44, no. 6, pp. 1701-1713, 2008.

[49] J. L. West and J. A. Hubbell, "Photopolymerized hydrogel materials for drug delivery applications," Reactive Polymers, vol. 25, no. 2-3, pp. 139-147, 1995.

[50] P. N. Le, C. K. Huynh, and N. Q. Tran, "Advances in thermosensitive polymer-grafted platforms for biomedical applications," Materials Science and Engineering: C, vol. 92, pp. 1016-1030, 2018.

[51] Y. Hongbo, Preparation of Temperature-Sensitive Hydrogels and Research on its In-Vitro Anti-Tumor Effect of under Co-Loading of VPA and Anti-Tumor Drugs, Jilin University, 2017.

[52] S. Van Vlierberghe, P. Dubruel, and E. Schacht, "Biopolymer-based hydrogels as scaffolds for tissue engineering applications: a review," Biomacromolecules, vol. 12, no. 5, pp. 1387-1408, 2011.

[53] C. L. Peng, Y. H. Shih, K. S. Liang et al., "Development of in situ forming thermosensitive hydrogel for radiotherapy combined with chemotherapy in a mouse model of hepatocellular carcinoma," Molecular Pharmaceutics, vol. 10, no. 5, pp. 1854-1864, 2013.

[54] T. Yu, Preparation of Chitosan-Based Temperature-Sensitive Compound Hydrogels and its Properties, Changsha University of Science and Technology, 2011.

[55] G. C. Dong, C. Y. Kuan, S. Subramaniam et al., "A potent inhibition of oxidative stress induced gene expression in neural cells by sustained ferulic acid release from chitosan based hydrogel," Materials Science \& Engineering. C, Materials for Biological Applications, vol. 49, pp. 691-699, 2015.

[56] H. Y. Liu and X. X. Zhu, "Lower critical solution temperatures of $\mathrm{N}$-substituted acrylamide copolymers in aqueous solutions," Polymer, vol. 40, no. 25, pp. 6985-6990, 1999.

[57] N. Rasool, T. Yasin, J. Y. Y. Heng, and Z. Akhter, "Synthesis and characterization of novel $\mathrm{pH}$-, ionic strength and temperature- sensitive hydrogel for insulin delivery," Polymer, vol. 51, no. 8 , pp. $1687-1693,2010$.
[58] M. Ikeda, T. Tanida, T. Yoshii et al., "Installing logic-gate responses to a variety of biological substances in supramolecular hydrogel-enzyme hybrids," Nature Chemistry, vol. 6, no. 6, pp. 511-518, 2014

[59] C. Gao, J. Ren, W. Kong, R. Sun, and Q. Chen, "Comparative study on temperature/pH sensitive xylan-based hydrogels: their properties and drug controlled release," RSC Advances, vol. 5, no. 110, pp. 90671-90681, 2015.

[60] G. Yubo, Controlled Drug Release of pH/Temperature-Sensitive Glycine Ester - Sodium Alginate Hydrogels Based on Poly N-Acroloyl, Hebei University, 2011.

[61] T. R. Hoare and D. S. Kohane, "Hydrogels in drug delivery: progress and challenges," Polymer, vol. 49, no. 8, pp. 19932007, 2008

[62] C. T. Huynh, M. K. Nguyen, D. P. Huynh, S. W. Kim, and D. S. Lee, "pH/temperature-sensitive 4-arm poly(ethylene glycol)poly(amino urethane) copolymer hydrogels," Polymer, vol. 51, no. 17, pp. 3843-3850, 2010.

[63] C. T. Huynh, M. K. Nguyen, J. H. Kim, S. W. Kang, B. S. Kim, and D. S. Lee, "Sustained delivery of doxorubicin using biodegradable $\mathrm{pH} /$ temperature-sensitive poly(ethylene glycol)-poly( $\beta$-amino ester urethane) multiblock copolymer hydrogels," Soft Matter, vol. 7, no. 10, p. 4974, 2011.

[64] Y. L. Lo, C. Y. Hsu, and H. R. Lin, "pH-and thermo-sensitive pluronic/poly(acrylic acid) in situ hydrogels for sustained release of an anticancer drug," Journal of Drug Targeting, vol. 21, no. 1, pp. 54-66, 2012.

[65] S. H. Seo, H. D. Han, K. H. Noh, T. W. Kim, and S. W. Son, "Chitosan hydrogel containing GMCSF and a cancer drug exerts synergistic anti-tumor effects via the induction of CD8 + T cell-mediated anti-tumor immunity," Clinical \& Experimental Metastasis, vol. 26, no. 3, pp. 179-187, 2009.

[66] I. Katime, J. R. Quintana, N. E. Valderruten, and L. C. Cesteros, "Synthesis and properties of $\mathrm{pH}$ - and temperature-sensitive poly[(N-isopropylacrylamide)-co-(2-methylenebutane-1,4dioic acid)] hydrogels," Macromolecular Chemistry and Physics, vol. 207, no. 22, pp. 2121-2127, 2006.

[67] T. Hoare and R. Pelton, "Highly $\mathrm{pH}$ and temperature responsive microgels functionalized with vinylacetic acid," Macromolecules, vol. 37, no. 7, pp. 2544-2550, 2004.

[68] Y. Huang and X. Luo, "Studies on the Controlled release of aspirin in the temperature/pH sensitive hydrogels," Polymer Materials Science and Engineering, vol. 14, no. 6, pp. 141143,1998

[69] C. Ramkissoon-Ganorkar, F. Liu, M. Baudyš, and S. W. Kim, "Modulating insulin-release profile from $\mathrm{pH} /$ thermosensitive polymeric beads through polymer molecular weight," Journal of Controlled Release, vol. 59, no. 3, pp. 287-298, 1999.

[70] C. T. Huynh, M. K. Nguyen, and D. S. Lee, "Biodegradable $\mathrm{pH} /$ temperature-sensitive oligo( $\beta$-amino ester urethane) hydrogels for controlled release of doxorubicin," Acta Biomaterialia, vol. 7, no. 8, pp. 3123-3130, 2011.

[71] C. Ding, L. Zhao, F. Liu et al., "Dually responsive injectable hydrogel prepared by in situ cross-linking of glycol chitosan and benzaldehyde-capped PEO-PPO-PEO," Biomacromolecules, vol. 11, no. 4, pp. 1043-1051, 2010.

[72] B. L. Guo and Q. Y. Gao, "Preparation and properties of a $\mathrm{pH} /$ temperature-responsive carboxymethyl chitosan/poly $(\mathrm{N}$ isopropylacrylamide)semi-IPN hydrogel for oral delivery of drugs," Carbohydrate Research, vol. 342, no. 16, pp. 24162422, 2007. 
[73] G. Wang and Y. Li, "Preparation of pH-sensitive hydrogels based on hemicellulose and its drug release property," Modern Chemical Industry, vol. 32, no. 5, pp. 62-66, 2012.

[74] A. Islam and T. Yasin, "Controlled delivery of drug from $\mathrm{pH}$ sensitive chitosan/poly (vinyl alcohol) blend," Carbohydrate Polymers, vol. 88, no. 3, pp. 1055-1060, 2012.

[75] A. Bilia, V. Carelli, G. di Colo, and E. Nannipieri, "In vitro evaluation of a $\mathrm{pH}$-sensitive hydrogel for control of GI drug delivery from silicone-based matrices," International Journal of Pharmaceutics, vol. 130, no. 1, pp. 83-92, 1996.

[76] M. V. Risbud, A. A. Hardikar, S. V. Bhat, and R. R. Bhonde, "pH-sensitive freeze-dried chitosan-polyvinyl pyrrolidone hydrogels as controlled release system for antibiotic delivery," Journal of Controlled Release, vol. 68, no. 1, pp. 23-30, 2000.

[77] Y. Cheng, C. He, J. Ding, C. Xiao, X. Zhuang, and X. Chen, "Thermosensitive hydrogels based on polypeptides for localized and sustained delivery of anticancer drugs," Biomaterials, vol. 34, no. 38, pp. 10338-10347, 2013.

[78] F. Chen, S. Song, H. Wang et al., "Injectable chitosan thermogels for sustained and localized delivery of pingyangmycin in vascular malformations," International Journal of Pharmaceutics, vol. 476, no. 1-2, pp. 232-240, 2014.

[79] J. Liu, Y. Jiang, Y. Cui, C. Xu, X. Ji, and Y. Luan, “CytarabineAOT catanionic vesicle-loaded biodegradable thermosensitive hydrogel as an efficient cytarabine delivery system," International Journal of Pharmaceutics, vol. 473, no. 1-2, pp. 560571, 2014.

[80] C. Cheng, D. Xia, X. Zhang, L. Chen, and Q. Zhang, "Biocompatible poly ( $\mathrm{N}$-isopropylacrylamide)-g-carboxymethyl chitosan hydrogels as carriers for sustained release of cisplatin," Journal of Materials Science, vol. 50, no. 14, pp. 4914-4925, 2015.

[81] S. Brahima, C. Boztepe, A. Kunkul, and M. Yuceer, "Modeling of drug release behavior of $\mathrm{pH}$ and temperature sensitive poly(NIPAAm- co -AAc) IPN hydrogels using response surface methodology and artificial neural networks," Materials Science and Engineering: C, vol. 75, pp. 425-432, 2017.

[82] C. Mircioiu, V. Voicu, V. Anuta et al., "Mathematical modeling of release kinetics from supramolecular drug delivery systems," Pharmaceutics, vol. 11, no. 3, p. 140, 2019.

[83] T. Irimia, M. Ghica, L. Popa, V. Anuța, A. L. Arsene, and C. E. Dinu-Pîrvu, "Strategies for improving ocular drug bioavailability and corneal wound healing with Chitosan-based delivery systems," Polymers, vol. 10, no. 11, p. 1221, 2018.

[84] H. Badie and H. Abbas, "Novel small self-assembled resveratrol-bearing cubosomes and hexosomes: preparation, charachterization, and ex vivo permeation," Drug Development and Industrial Pharmacy, vol. 44, no. 12, pp. 20132025, 2018.

[85] M. Qindeel, N. Ahmed, F. Sabir, S. Khan, and A. Ur-Rehman, "Development of novel pH-sensitive nanoparticles loaded hydrogel for transdermal drug delivery," Drug Development and Industrial Pharmacy, vol. 45, no. 4, pp. 629-641, 2019. 